\title{
ASSIMILAÇÃO E PENETRAÇÃO DE FASE LÍQUIDA EM MINÉRIO DE FERRO*
}

\author{
Thiago Pinto Silva ${ }^{1}$ \\ Renata Cristina Alves Elias ${ }^{2}$ \\ Beatriz Fausta Gandra ${ }^{3}$
}

\begin{abstract}
Resumo
A Usiminas implementou dois ensaios para caracterização de minérios de ferro na sinterização, intitulados assimilação e penetração de fase líquida. O primeiro tem como objetivo avaliar as fases mineralógicas, a formação de poros e a resistência mecânica de partículas nucleantes e aderentes por meio da reação do minério com o calcário. O segundo objetiva medir o comprimento da penetração da fase líquida formada entre a calcioferrita e o minério. No presente trabalho, são descritas as principais características e potencialidades desses novos testes, os quais foram utilizados para a avaliação do comportamento metalúrgico de seis minérios distintos. Os resultados obtidos de assimilação e de penetração da fase líquida foram comparados com as características mineralógicas e químicas dos minérios, sendo observada uma boa correlação entre essas características e os resultados dos novos testes. Verificou-se também que a análise tradicional do minério não é suficiente para estimar seu comportamento metalúrgico na sinterização, o que reforça a importância da utilização dos novos testes implementados. Além disso, permitem avaliar o comportamento dos minérios em altas temperaturas, auxiliando na escolha da carga de minérios mais adequada para a sinterização.
\end{abstract}

Palavras-chave: Assimilação; Penetração; Sinter feed; Sinterização.

\begin{abstract}
Usiminas has implemented two tests for iron ore characterization, named assimilation and melt penetration. The first one evaluates the mineralogical phases, pore structure and mechanical strength of nucleating and adhering particles by the reaction between iron ore with limestone. The former aims to measure the length of melt penetration between the ore and calcium ferrite. In this paper, it was describe the main characteristics and potential of these new tests, which were used to evaluate the metallurgical behavior of six different iron ores. The results of assimilation and melt penetration were compared with the mineralogical and chemical of the ores. Good correlation between these characteristics and results of new tests was observed. It was also found that the traditional analysis of the ore is not sufficient to estimate its metallurgical sintering behavior, which reinforces the importance of the new tests. Moreover, those tests can evaluate the behavior of iron ores at high temperatures, helping to choose the most suitable iron ore burden for sintering process.
\end{abstract}

ASSIMILATION AND MELT PENETRATION OF IRON ORE

Keywords: Assimilation; Melt Penetration; Sinter feed; Sintering.

1 Engenheiro Metalurgista, Pesquisador, Centro de Tecnologia, Usiminas, Membro da ABM, Ipatinga, MG, Brasil.

2 Engenheira Química, M.Sc., Pesquisadora, Centro de Tecnologia, Usiminas, Ipatinga, MG, Brasil.

3 Engenheira Metalurgista, M.Sc., Pesquisadora, Centro de Tecnologia, Usiminas, Membro da $A B M$, Ipatinga, MG, Brasil.

\footnotetext{
* Contribuição técnica ao $44^{\circ}$ Seminário de Redução de Minério de Ferro e Matérias-primas, 15ํ Simpósio Brasileiro de Minério de Ferro e $2^{\circ}$ Simpósio Brasileiro de Aglomeração de Minério de Ferro, 15 a 18 de setembro de 2014, Belo Horizonte, MG, Brasil.
} 


\section{INTRODUÇÃO}

De maneira geral, tem-se observado as sinterizações brasileiras trabalhando com minérios de qualidade cada vez inferior, devido à elevação da explotação de itabiritos. Neste contexto, o conhecimento das propriedades intrínsecas dos minérios de ferro se torna fundamental para avaliar sua influência no comportamento da carga metálica, tanto na sinterização quanto no alto-forno. No caso da sinterização, a definição da mistura de minérios adequada passa a ser um vetor importante para minimização dos possíveis prejuízos operacionais.

A Usiminas caracterizava o sinter feed, até então, por meio de suas propriedades básicas (composição química, granulométrica e mineralógica). O comportamento em altas temperaturas (propriedades metalúrgicas) passou a ser avaliado por meio dos ensaios assimilação e penetração de fase líquida, desenvolvidos pela Nippon Steel \& Sumitomo Metal Corporation (NSSMC). Tais propriedades do líquido vêm sendo estudadas por diversos autores [1-5], visando encontrar a utilização mais adequada do minério na sinterização.

O ensaio assimilação é utilizado para avaliar a mudança na forma, a estrutura dos poros, a microestrutura e a resistência física do sínter produzido a partir do minério com calcário. Já o ensaio penetração de fase líquida tem como objetivo determinar a capacidade de difusão do líquido durante a reação do minério com a calcioferrita. $O$ teste não quantifica o volume de líquido que penetra efetivamente na camada e sim o comprimento da sua penetração.

Okazaki et al. [1] ao avaliarem o comprimento de penetração do líquido em diversos minérios verificaram que esse índice é influenciado pela morfologia do minério antes e depois do aquecimento e da sua composição química.

No presente trabalho, são descritas as principais características e potencialidades desses novos testes, os quais foram utilizados para avaliar o comportamento metalúrgico de seis minérios distintos.

\section{MATERIAIS E MÉTODOS}

\subsection{Determinação das Propriedades Básicas dos Minérios}

As propriedades básicas de seis minérios foram avaliadas pelas seguintes técnicas e/ou ensaios:

- composição química, sendo $\mathrm{Fe}$ e e $\mathrm{FeO}$ por volumetria, $\mathrm{CaO}, \mathrm{SiO}_{2}$ e $\mathrm{Al}_{2} \mathrm{O}_{3}$ por espectrometria de fluorescência de raios-X e a perda por calcinação (PPC) via termogravimetria;

- mineralogia por contagem de pontos (500 por amostra), usando microscópio óptico; e,

- porosimetria por intrusão de $\mathrm{Hg}$, usando a fração $2,0 \mathrm{~mm}$ a $2,8 \mathrm{~mm}$ do minério.

\footnotetext{
* Contribuição técnica ao $44^{\circ}$ Seminário de Redução de Minério de Ferro e Matérias-primas, 15ํ Simpósio Brasileiro de Minério de Ferro e $2^{\circ}$ Simpósio Brasileiro de Aglomeração de Minério de Ferro, 15 a 18 de setembro de 2014, Belo Horizonte, MG, Brasil.
} 


\subsection{Determinação das Propriedades Metalúrgicas}

\subsubsection{Assimilação com CaO}

A assimilação dos minérios com o calcário foi avaliada considerando a configuração da quase partícula que pode ser dividida em duas regiões: nucleante e aderente.

A reação entre minério e calcário na região nucleante foi avaliada por meio da preparação de quase partículas, aglomerando com água o minério $(2,0 \mathrm{~mm}$ a $2,8 \mathrm{~mm}$ ) com o undersize do calcário classificado em $0,5 \mathrm{~mm}$ (figura 1a). A relação entre as duas matérias primas ( $\mathrm{CaO} /$ minério) foi 0,1 . Os agregados foram adicionados num cadinho de níquel e aquecidos ao ar até $1300^{\circ} \mathrm{C}$, sendo de $1100^{\circ} \mathrm{C}$ a $1300^{\circ} \mathrm{C}$ em $1 \mathrm{~min}$ e no resfriamento, também ao ar, de $1300{ }^{\circ} \mathrm{C}$ a $1100{ }^{\circ} \mathrm{C}$ em 3 min. Foi fabricado um corpo de prova para análise ao microscópio óptico.

A outra região (aderente) foi avaliada misturando com água os undersizes do minério e do calcário classificados em $0,5 \mathrm{~mm}$. A relação entre as duas matérias primas ( $\mathrm{CaO} /$ minério) foi 0,1 . A mistura foi compactada a $2 \mathrm{MPa}$ durante $30 \mathrm{~s}$, produzindo um corpo de prova cilíndrico (figura $1 \mathrm{~b}$ ). $\mathrm{O}$ processamento térmico foi $\mathrm{o}$ mesmo realizado para às quase partículas. Neste caso, quatro corpos de prova foram fabricados, um para avaliação ao microscópio óptico e três para medição da resistência mecânica. Essa medição foi realizada deixando cair três vezes um peso com $300 \mathrm{~g}$ na amostra de sínter e em seguida classificando-o. O índice foi calculado pela porcentagem retida na malha de $0,5 \mathrm{~mm}$.

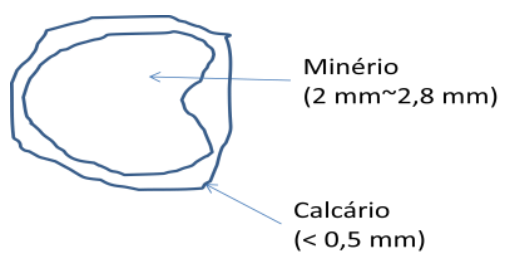

(a) quase partículas

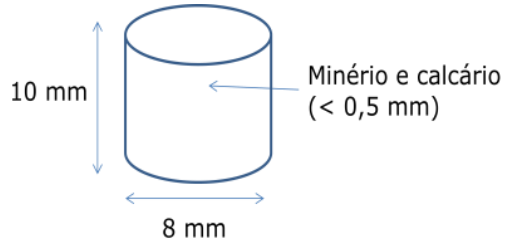

(b) tablet

Figura 1. Desenho esquemático dos corpos de prova do ensaio assimilação.

O processo térmico foi realizado em um dilatômetro de haste horizontal, sendo adaptado para os ensaios assimilação e penetração de fase líquida (figura 2).

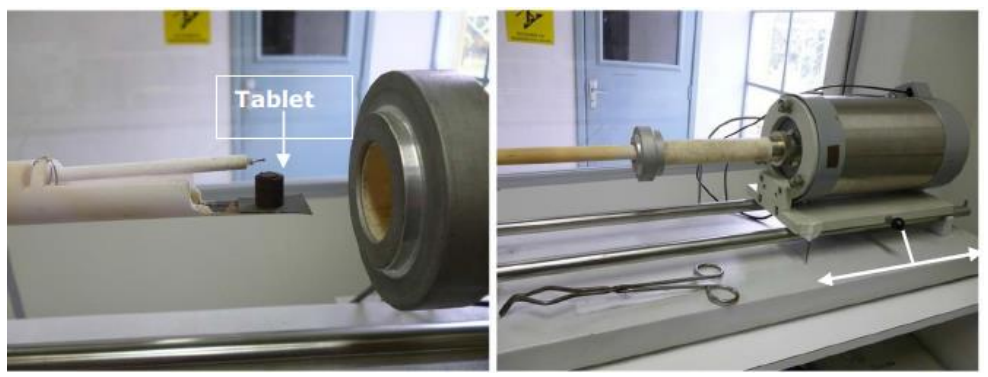

Figura 2. Detalhes do dilatômetro com haste horizontal adaptado para os testes assimilação e penetração.

A amostra destinada a análise microscópica foi embutida em resina de cura lenta, cortada conforme desenho esquemático mostrado nas figuras $3 a$ e $3 b$, frações nucleante e aderente, respectivamente, e levada à politriz semiautomática. As fases mineralógicas do sínter referente ao ensaio assimilação da fração aderente foram quantificadas por análise de imagem com o uso de um software específico.

\footnotetext{
* Contribuição técnica ao $44^{\circ}$ Seminário de Redução de Minério de Ferro e Matérias-primas, 15ํ Simpósio Brasileiro de Minério de Ferro e $2^{\circ}$ Simpósio Brasileiro de Aglomeração de Minério de Ferro, 15 a 18 de setembro de 2014, Belo Horizonte, MG, Brasil.
} 


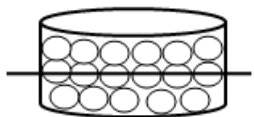

(a) fração nucleante

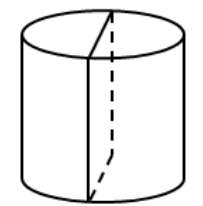

(b) fração aderente

Figura 3. Detalhes do corte nos corpos de prova do ensaio assimilação.

\subsubsection{Penetração de fase líquida}

O espalhamento do líquido na região aderente da quase partícula foi avaliado pela medição da profundidade de penetração do líquido. Na figura 4 são mostrados os corpos de prova, sendo um de minério (undersize classificado em $0,5 \mathrm{~mm}$ ) e o outro fabricado com os reagentes químicos $\mathrm{Fe}_{2} \mathrm{O}_{3}$ e $\mathrm{CaO}$.

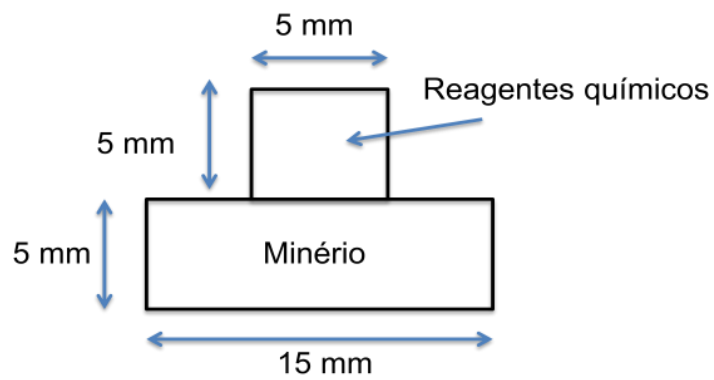

Figura 4. Desenho esquemático dos corpos de prova do ensaio penetração de fase líquida.

O primeiro corpo de prova, que serviu de base, foi fabricado misturando o minério com água durante $30 \mathrm{~s}$. Em seguida, fez-se a prensagem dessa mistura a $2 \mathrm{MPa}$ por $30 \mathrm{~s}$. O outro corpo de prova foi fabricado misturando os reagentes químicos $\mathrm{Fe}_{2} \mathrm{O}_{3}$ e $\mathrm{CaO}$ em um grau de ágata durante 2 min, seguindo a relação $\mathrm{CaO} / \mathrm{Fe}_{2} \mathrm{O}_{3}$ igual a 0,35 . Esta mistura foi prensada a $2 \mathrm{MPa}$ por $30 \mathrm{~s}$. O processo térmico foi igual aquele realizado no ensaio assimilação, produzindo-se uma amostra para análise ao microscópio óptico.

A amostra do ensaio penetração de fase líquida foi cortada ao meio longitudinalmente, sendo preparada da mesma forma que as amostras do ensaio assimilação para análise ao microscópio óptico, onde se mediu o comprimento de penetração, usando um software específico. Para isso foi adotada a metodologia proposta por Okazaki et al. [1], em que marca-se cinco posições no corpo de prova e mede-se o comprimento do centro e a $1 / 4$ de distância do centro, conforme mostrado na figura 5. O valor médio dessas posições expressará o comprimento de penetração da fase líquida do teste.

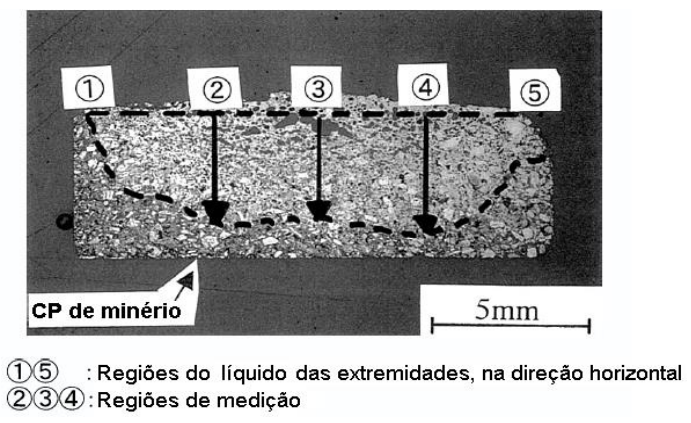

Figura 5. Determinação do comprimento de penetração [1].

\footnotetext{
* Contribuição técnica ao $44^{\circ}$ Seminário de Redução de Minério de Ferro e Matérias-primas, 15오 Simpósio Brasileiro de Minério de Ferro e 2ํ Simpósio Brasileiro de Aglomeração de Minério de Ferro, 15 a 18 de setembro de 2014, Belo Horizonte, MG, Brasil.
} 


\section{RESULTADOS E DISCUSSÃO}

\subsection{Propriedades Básicas}

\subsubsection{Composição química}

$\mathrm{Na}$ figura 6 é mostrada a composição química dos seis minérios e de suas frações $2,0 \mathrm{~mm}$ a $2,8 \mathrm{~mm}$ e menor que $0,5 \mathrm{~mm}$.

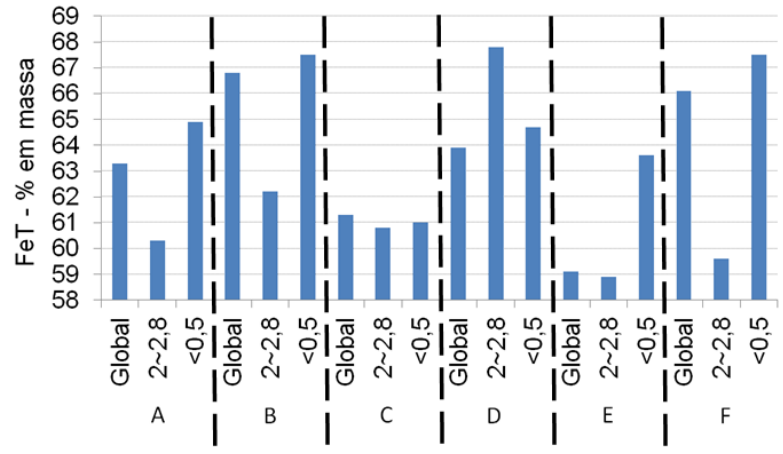

(a) $\mathrm{Fe}_{\mathrm{T}}$

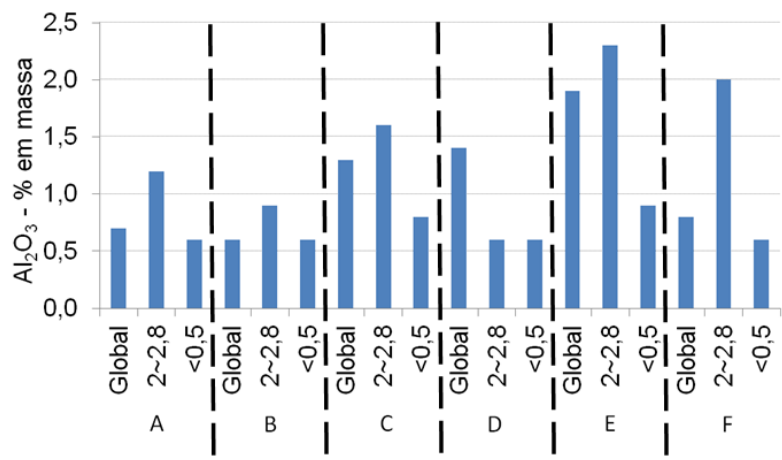

(c) $\mathrm{Al}_{2} \mathrm{O}_{3}$

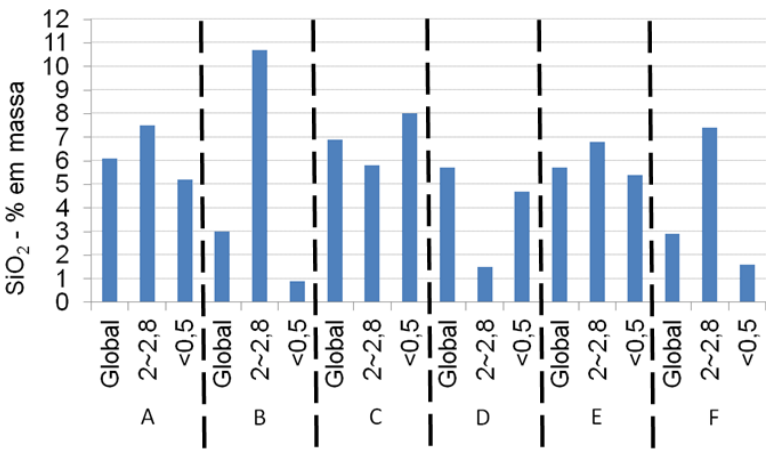

(b) $\mathrm{SiO}_{2}$

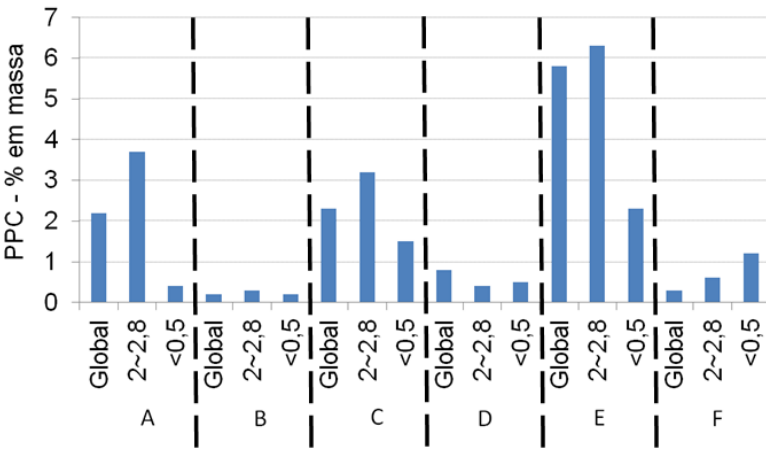

(d) PPC

Figura 6. Composição química dos minérios estudados.

Em relação à composição global dos minérios, observou-se que:

- B apresentou o maior teor de ferro seguido por F, D, A, C e E;

- F apresentou o menor teor de $\mathrm{SiO}_{2}$ seguido por $\mathrm{B}, \mathrm{E}, \mathrm{D}, \mathrm{A}$ e C;

- C, D e E apresentaram teores de $\mathrm{Al}_{2} \mathrm{O}_{3}$ superiores aos outros; $\mathrm{e}$,

- A, C e E apresentaram maior PPC que os minérios $B, D$ e $F$.

\subsubsection{Composição mineralógica}

Na figura 7 é mostrada a composição mineralógica dos minérios. Verifica-se que os minérios $\mathrm{A}, \mathrm{C}$ e $\mathrm{E}$ apresentaram maior teor de goethita que os demais, corroborando o maior PPC, sendo A e E com considerável quantidade de martita. Os minérios $B, D$ e F se mostraram hematíticos.

* Contribuição técnica ao $44^{\circ}$ Seminário de Redução de Minério de Ferro e Matérias-primas, 15ํ Simpósio Brasileiro de Minério de Ferro e $2^{\circ}$ Simpósio Brasileiro de Aglomeração de Minério de Ferro, 15 a 18 de setembro de 2014, Belo Horizonte, MG, Brasil. 


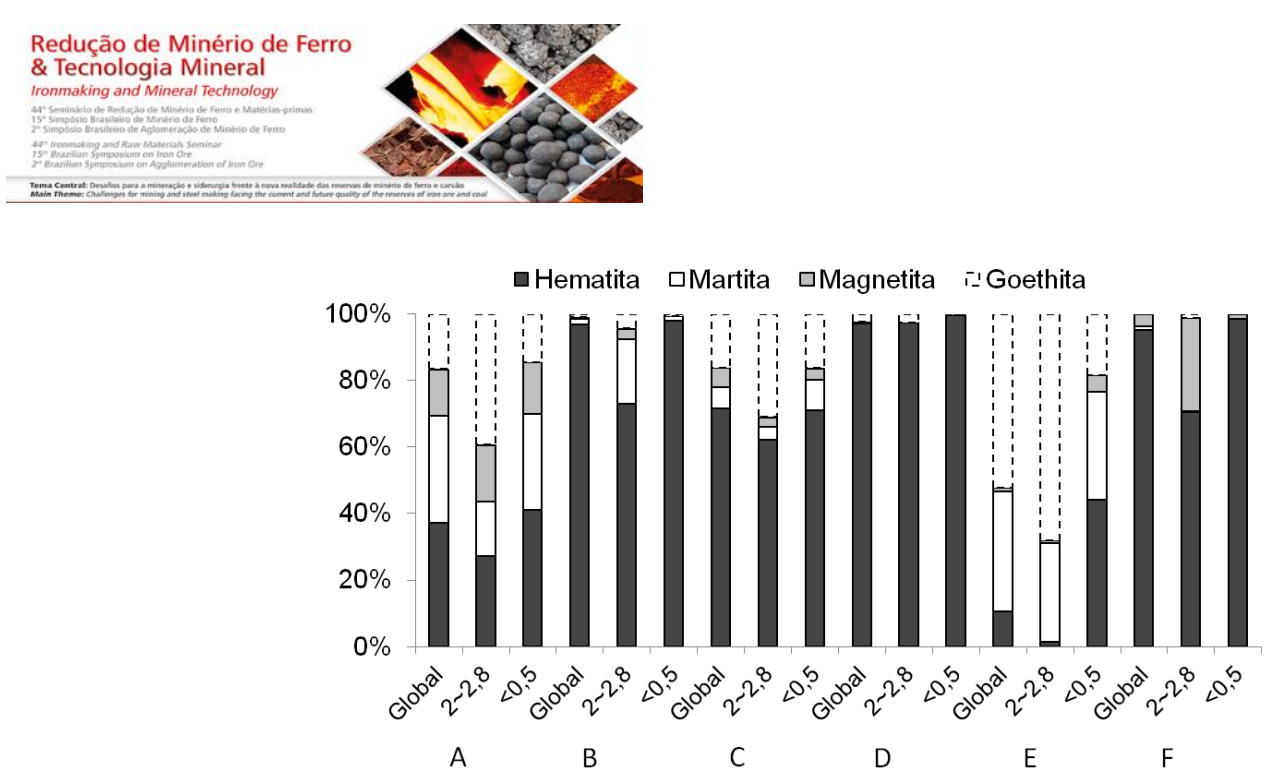

Figura 7. Composição mineralógica dos minérios estudados.

\subsubsection{Porosidade}

$\mathrm{Na}$ figura 8 é mostrada a porosidade da faixa nucleante dos minérios, sendo que $\mathrm{A}$, $\mathrm{C}$ e $\mathrm{E}$ apresentaram maior quantidade de poros quando comparados a $\mathrm{B}, \mathrm{D}$ e $\mathrm{F}$. Ressalta-se que esta porosidade se refere somente à faixa de poros $0,002 \mu \mathrm{m}$ a $360 \mu \mathrm{m}$.

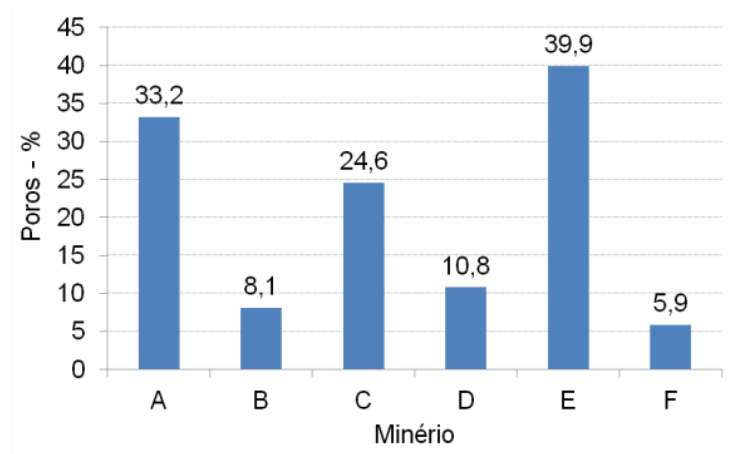

Figura 8. Porosidade da fração 2,0 mm 2,8 mm dos minérios (porosimetria por intrusão de $\mathrm{Hg}$ ).

\subsection{Propriedades Metalúrgicas}

\subsubsection{Assimilação com CaO}

A macroestrutura e a microestrutura dos sínteres após assimilação da fração nucleante são mostradas nas figuras 9 e 10, respectivamente. Nota-se que os minérios se comportaram de maneira diferente, sendo que $A, C$ e $E$ apresentaram partículas porosas e isoladas, enquanto que $\mathrm{B}, \mathrm{D}$ e $\mathrm{F}$ partículas aglomeradas. Ao avaliar suas microestruturas, notou-se a presença majoritária de Silico-ferrite of Calcium and Aluminum (SFCA) para os minérios B, D e F e de silicato para os minérios $\mathrm{A}, \mathrm{C}$ e $\mathrm{E}$.

$\mathrm{Na}$ figura 10 é possível notar nos minérios $\mathrm{C}$ e $\mathrm{E}$ estruturas com poro esférico, pequenas hematitas e SFCA, típica de goethita assimilada.

* Contribuição técnica ao 44ํㅗㄴ Seminário de Redução de Minério de Ferro e Matérias-primas, 15o Simpósio Brasileiro de Minério de Ferro e 2o Simpósio Brasileiro de Aglomeração de Minério de Ferro, 15 a 18 de setembro de 2014, Belo Horizonte, MG, Brasil. 

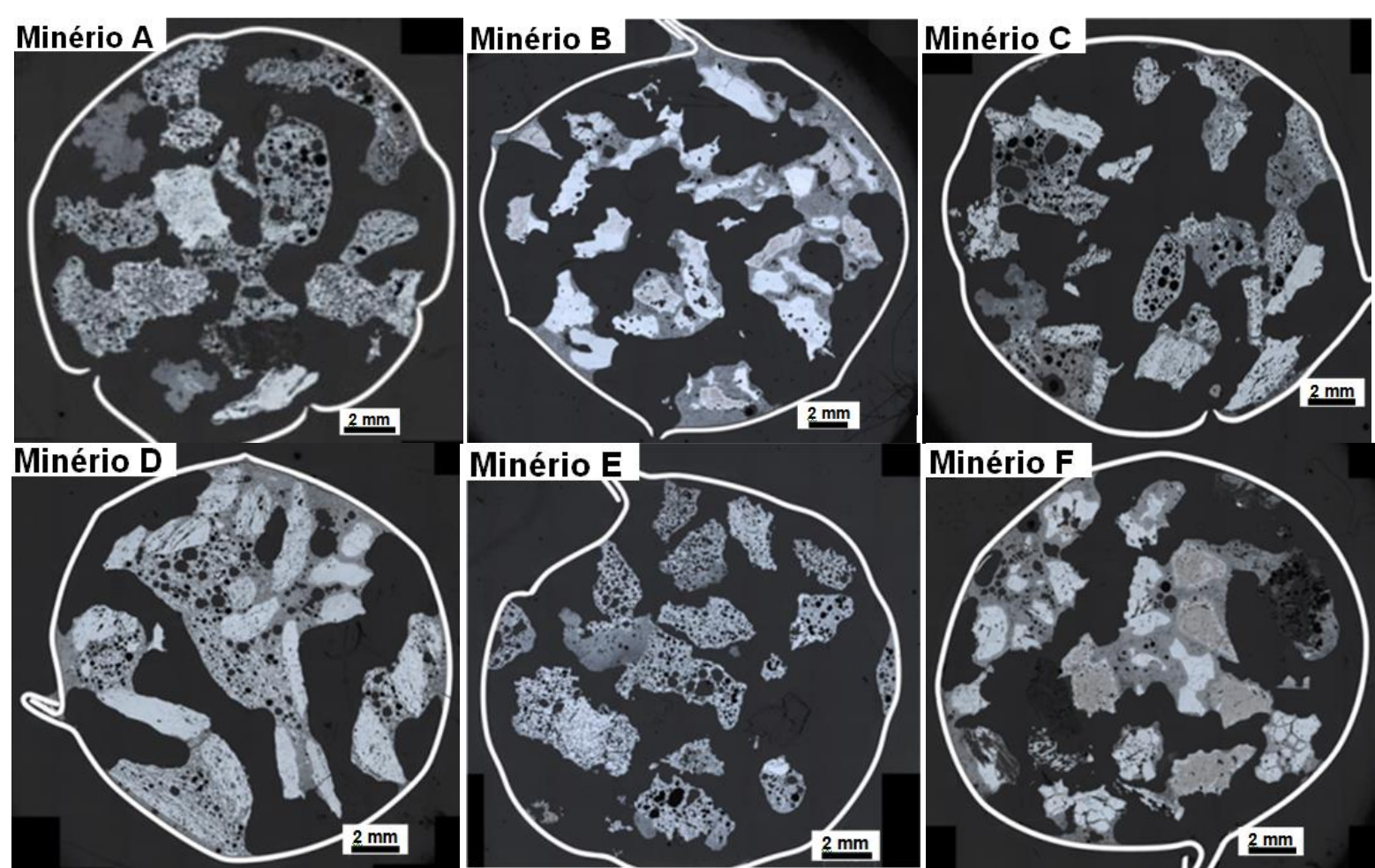

Figura 9. Macroestrutura dos sínteres após assimilação da fração nucleante do minério. (Aumento de 50x).

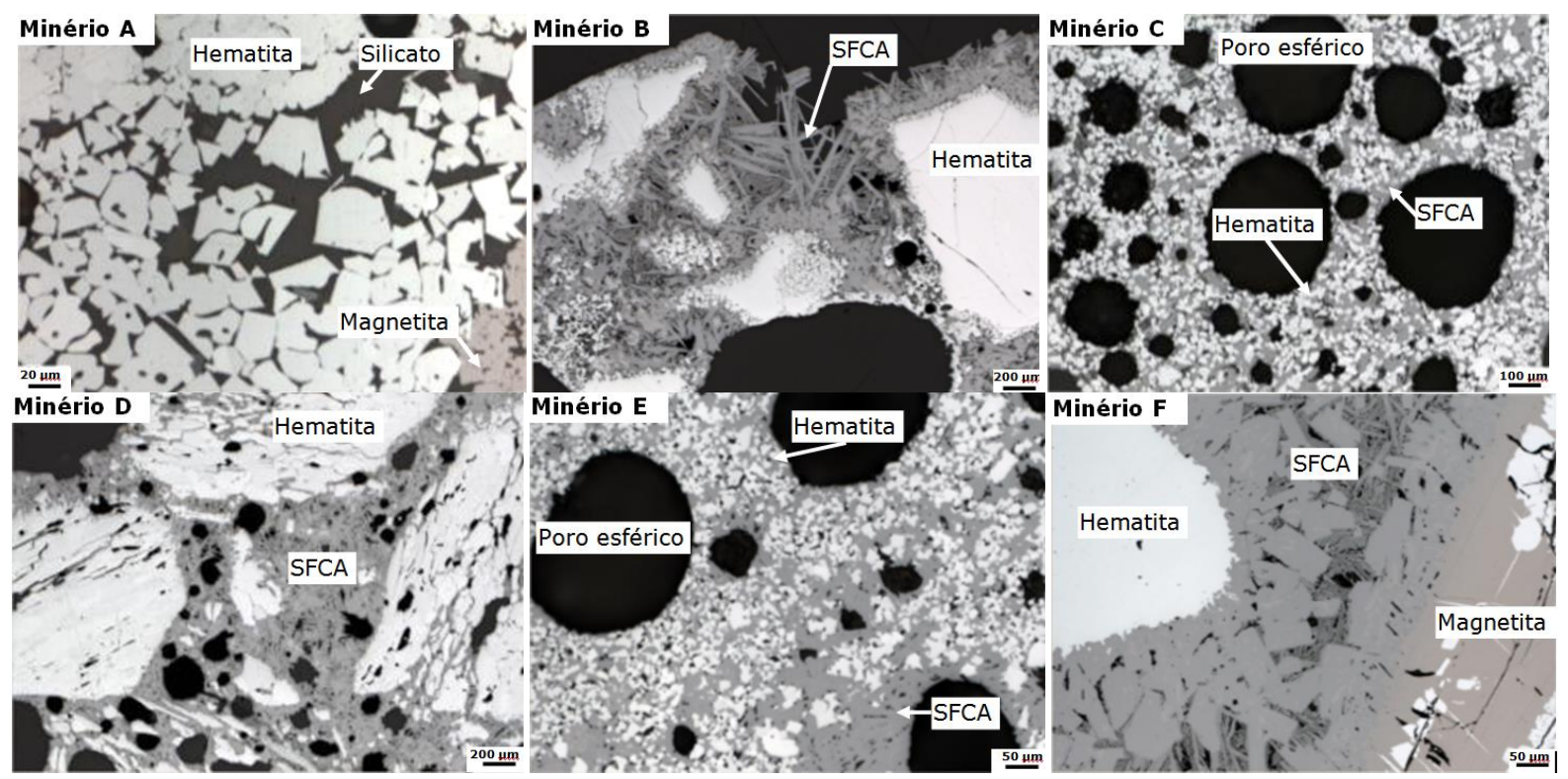

Figura 10. Microestrutura dos sínteres após assimilação da fração nucleante do minério.

(Aumento de 50x, 100x e 200x).

$A$ assimilação da fração nucleante dos minérios $A, C$ e $E$ foi maior que $B, D$ e $F$, devido a maior porosidade dos minérios, menor fluidez e menor quantidade de líquido disponível, configurando partículas isoladas.

Os minérios de maior porosidade assimilaram maior quantidade de líquido, faltando líquido para aglomerar outras partículas. Esses resultados concordam com aqueles apresentados por Denbricat [2].

* Contribuição técnica ao 44 Seminário de Redução de Minério de Ferro e Matérias-primas, 15은 Simpósio Brasileiro de Minério de Ferro e $2^{\circ}$ Simpósio Brasileiro de Aglomeração de Minério de Ferro, 15 a 18 de setembro de 2014, Belo Horizonte, MG, Brasil. 
As partículas porosas de sínter observadas em A, C e E (figura 9) são oriundas da goethita (também indicada pelo PPC) que, por se tratar de um mineral hidratado, gera poros ao passar pela desidratação, com isso, o líquido penetra na partícula, sendo assimilado quase que por completo.

Em relação aos sínteres oriundos dos minérios $B$, D e $F$ nota-se que as partículas de minérios foram pouco assimiladas e formaram SFCA que, por sua vez, serviram de ponte entre as outras partículas, estrutura considerada ideal para uma boa redutibilidade do sínter.

Nas figuras 11 e 12 são mostradas fotomicrografias da macroestrutura e microestrutura, respectivamente, do sínter após assimilação da fração aderente, das quais se pode inferir que:

- A, C e E apresentaram formatos similares e estrutura com poros irregulares;

- D apresentou uma estrutura um pouco mais compacta que aqueles citados anteriormente e com poros irregulares a esféricos;

- F apresentou uma estrutura compacta com pouco poro esférico; e,

- B apresentou formato achatado com pouco poro esférico.

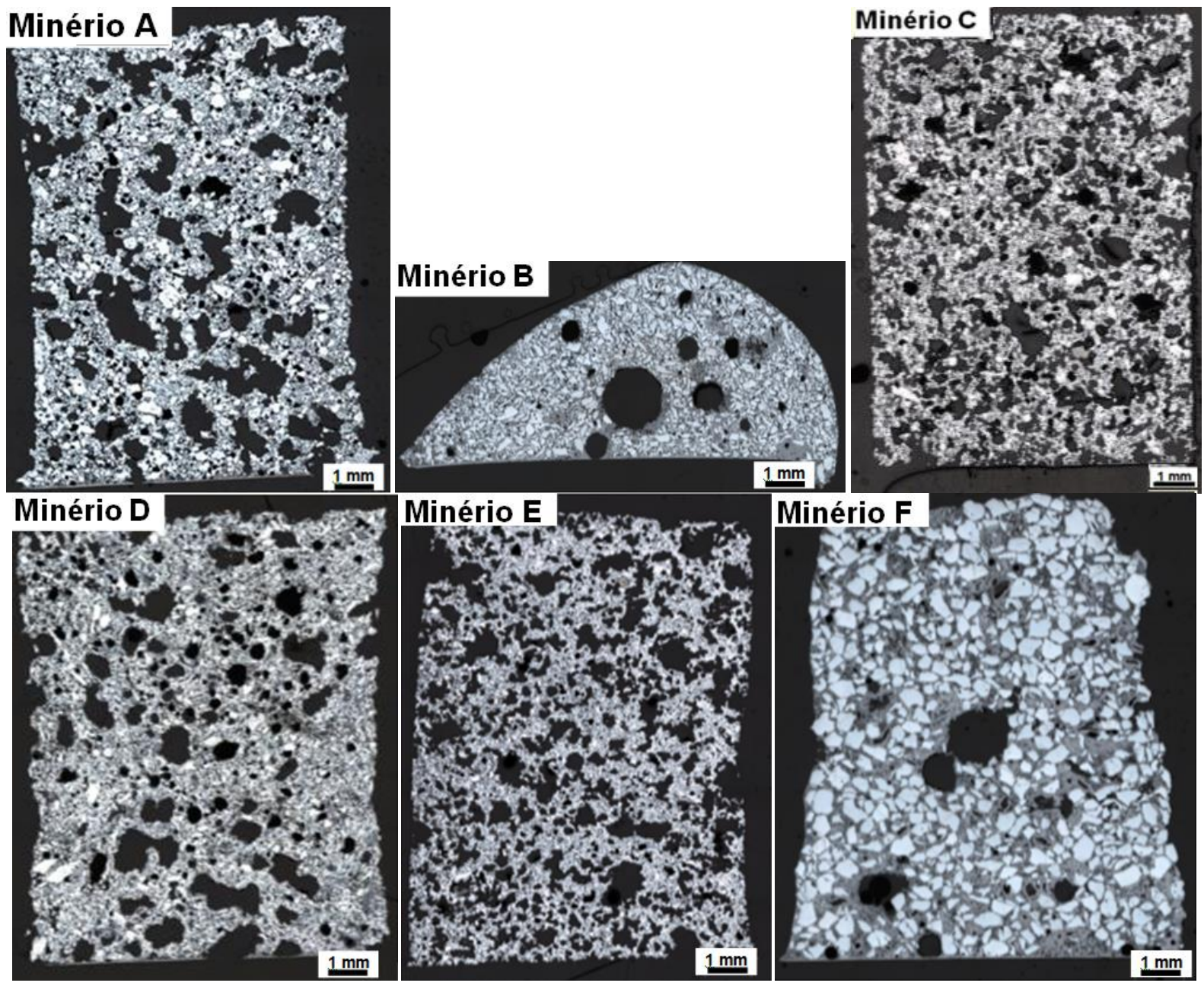

Figura 11. Macroestrutura dos sínteres após assimilação da fração aderente. (Aumento de 50x).

* Contribuição técnica ao $44^{\circ}$ Seminário de Redução de Minério de Ferro e Matérias-primas, 15ํ Simpósio Brasileiro de Minério de Ferro e $2^{\circ}$ Simpósio Brasileiro de Aglomeração de Minério de Ferro, 15 a 18 de setembro de 2014, Belo Horizonte, MG, Brasil. 

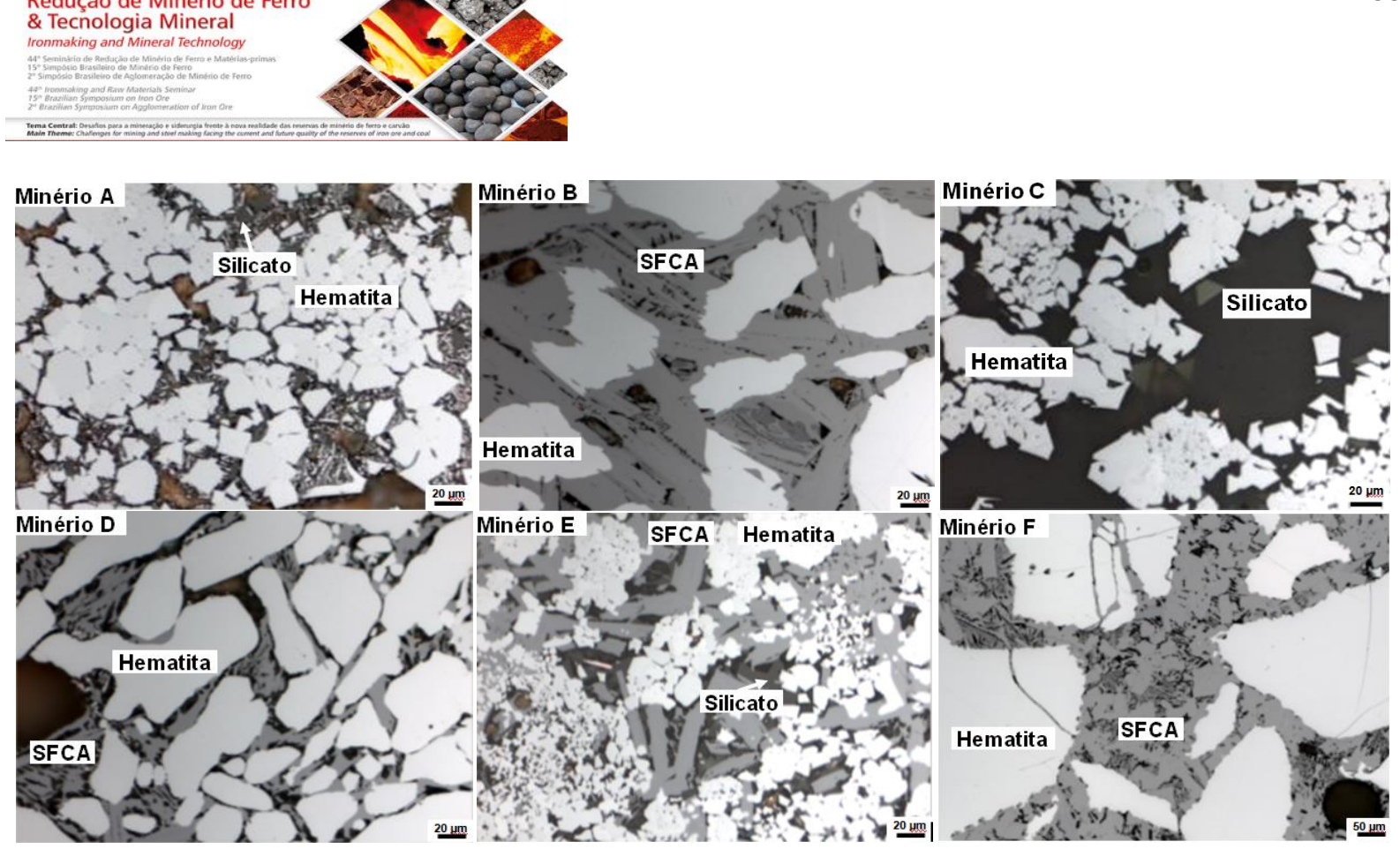

Figura 12. Microestrutura dos sínteres após assimilação da fração aderente.

(Aumento de 200x e 500x).

O formato dos poros nestes corpos de prova pode ser uma evidência da fluidez do líquido, sendo que os minérios ( $\mathrm{B}$ e $\mathrm{F}$ ) com menor teor de ganga tenderam a formar líquidos de maior fluidez e, com isso, poros esféricos. Por outro lado, minérios com maior teor de ganga ( $A, C$ e $E$ ) tenderam a formar líquidos de menor fluidez, formando poros irregulares. O minério $D$ que apresentou poros irregulares $e$ esféricos apresentou um líquido de fluidez intermediária.

A fração aderente dos minérios $B$ e $F$, apesar da similaridade química $e$ mineralógica, formaram sínteres com estruturas diferentes. Pode-se notar que o tamanho da partícula de hematita do minério $B$ é menor do que $F$ (figura 11), sendo essa a possível razão de tal diferença. No processo de sinterização, estes minérios formariam líquido em menor temperatura que $A, C, D$ e $E$ contribuindo, possivelmente, para o menor consumo de combustível e maior velocidade da frente de queima.

$\mathrm{Na}$ figura 13 são mostradas as composições mineralógicas dos sínteres. Nota-se que $\mathrm{B}$ e $\mathrm{F}$ apresentaram grande quantidade de SFCA.

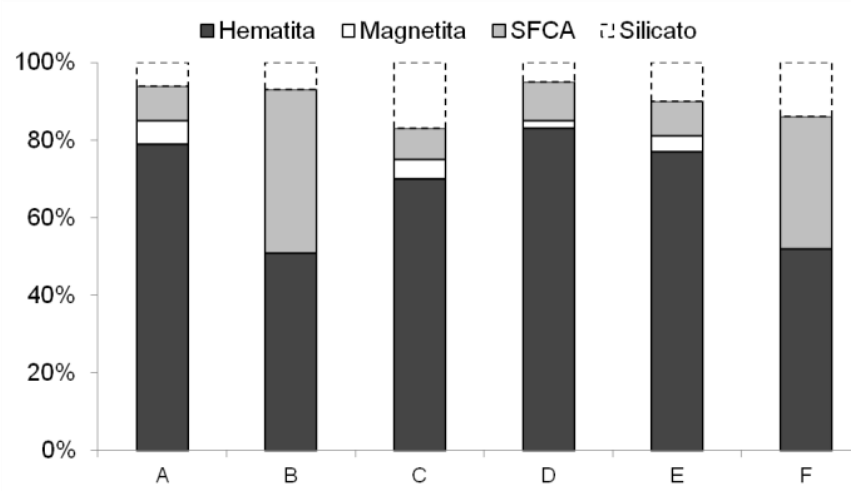

Figura 13. Composição mineralógica dos sínteres após assimilação da fração aderente.

\footnotetext{
* Contribuição técnica ao 44 Seminário de Redução de Minério de Ferro e Matérias-primas, 15ํ Simpósio Brasileiro de Minério de Ferro e $2^{\circ}$ Simpósio Brasileiro de Aglomeração de Minério de Ferro, 15 a 18 de setembro de 2014, Belo Horizonte, MG, Brasil.
} 
Na figura 14 é mostrada a resistência mecânica dos sínteres após assimilação da fração aderente. A maior resistência mecânica foi obtida pelo minério $F$ e a menor pelo minério $\mathrm{E}$.

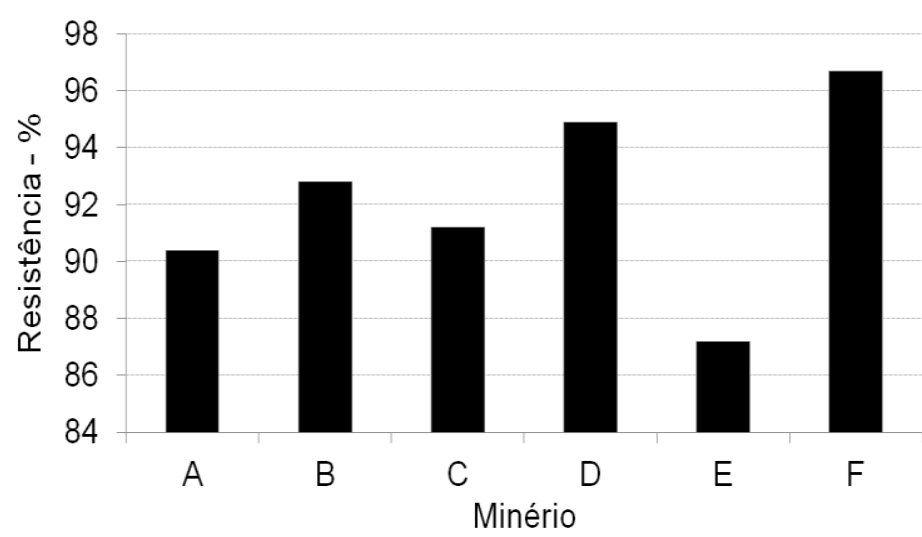

Figura 14. Resistência mecânica dos sínteres após assimilação da fração aderente do minério.

Na figura 15 são mostradas as principais relações que explicam o comportamento mecânico do sínter após assimilação, onde se nota relação direta para o ferro total e hematita, e relação indireta para o PPC, a alumina, a sílica, a martita e a goethita.
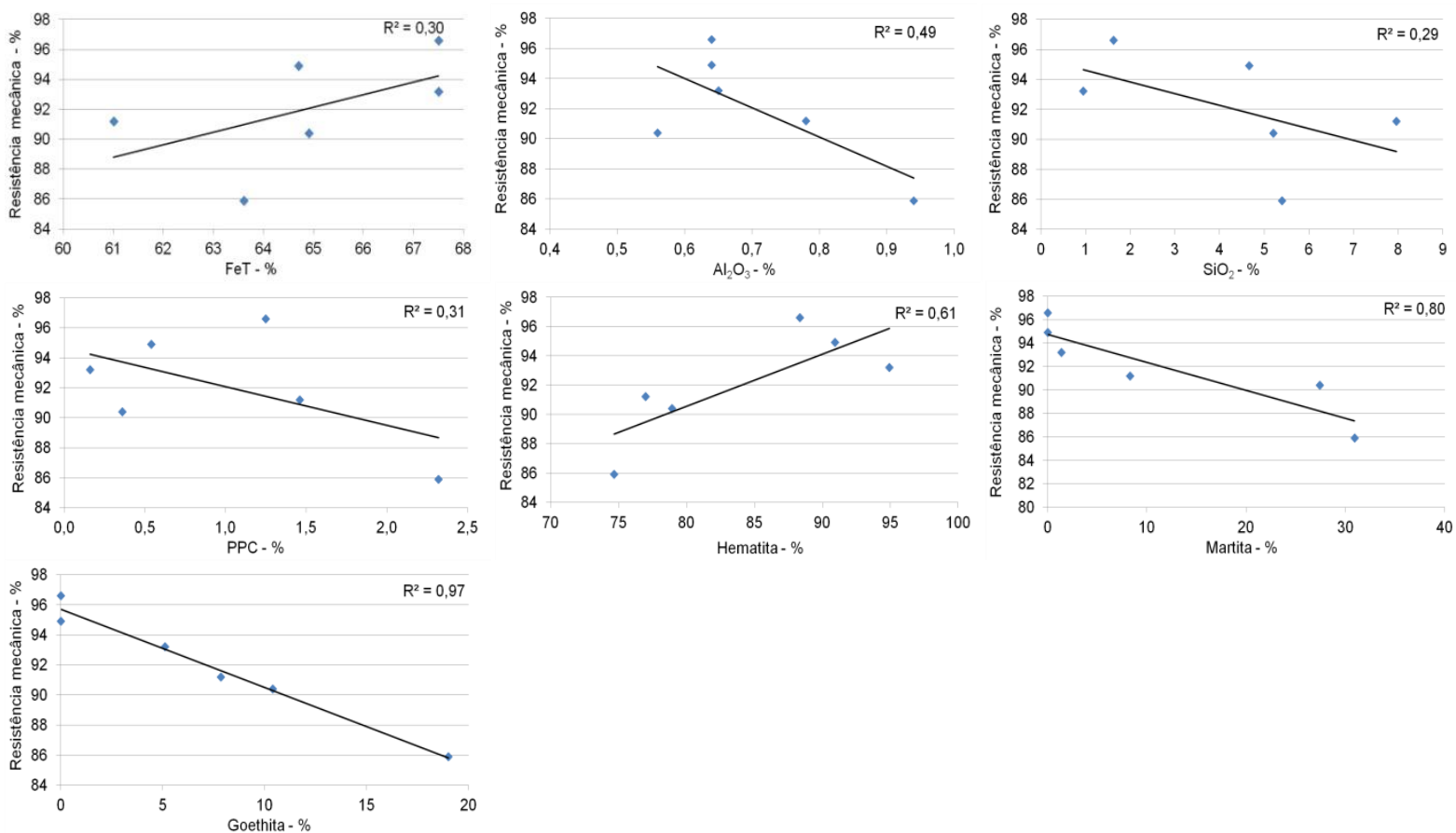

Figura 15. Relações entre a resistência mecânica dos sínteres após assimilação com as análises químicas e mineralógicas da fração aderente do minério.

Os resultados mostram que minérios hematíticos tendem a melhorar a resistência mecânica do sínter, enquanto que a presença de martita e goethita tendem a reduzir essa resistência.

A goethita, por se tratar de um mineral hidratado, gera poros ao passar pela desidratação, com isso, o líquido penetra na partícula, sendo assimilado quase que por completo, o que resulta em falta de líquido para ligar outras partículas, podendo reduzir a resistência do sínter. A relação entre resistência e alumina pode estar

* Contribuição técnica ao 44 Seminário de Redução de Minério de Ferro e Matérias-primas, 15ㅇ Simpósio Brasileiro de Minério de Ferro e 2o Simpósio Brasileiro de Aglomeração de Minério de Ferro, 15 a 18 de setembro de 2014, Belo Horizonte, MG, Brasil. 
ligada à presença da goethita que devido a sua formação geológica pode conter compostos como $\mathrm{Al}_{2} \mathrm{O}_{3}$. A martita, que pode ser encontrada porosa, contribuiu para a absorção do líquido, evitando que outras partículas fossem aglomeradas e reduzindo a resistência mecânica.

\subsubsection{Penetração de fase líquida}

$\mathrm{Na}$ figura 16 é mostrado o comprimento da penetração de fase líquida nos minérios avaliados, exceto no minério $\mathrm{F}$ que apresentou dificuldades em se manter rígido durante o processamento térmico. Observa-se que o minério $B$ apresentou o maior índice e o minério $\mathrm{C}$ o menor.

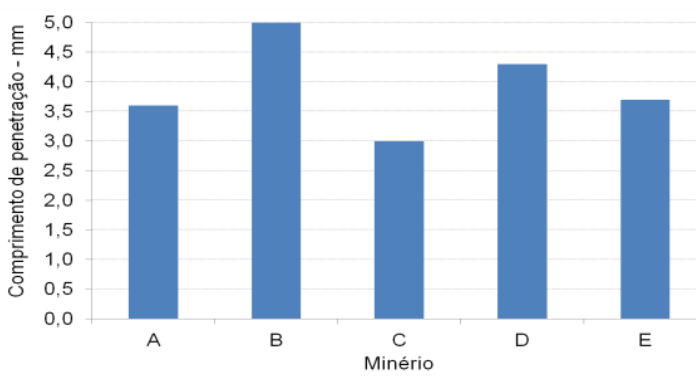

Figura 16. Comprimento da penetração do líquido nos minérios.

Para Okazaki et al. [1] minérios com maiores comprimentos de penetração favorecem a maior resistência e rendimento do sínter, ou seja, neste caso, os minérios $B$ e $D$ tendem a elevar tais indicadores.

$\mathrm{Na}$ figura 17 são mostradas as principais relações que explicam o comprimento da penetração de fase líquida, na qual se nota relação direta para o ferro total e a hematita, e relação indireta para o PPC, a alumina, a sílica, a martita e a goethita, assim como observado para o teste assimilação.
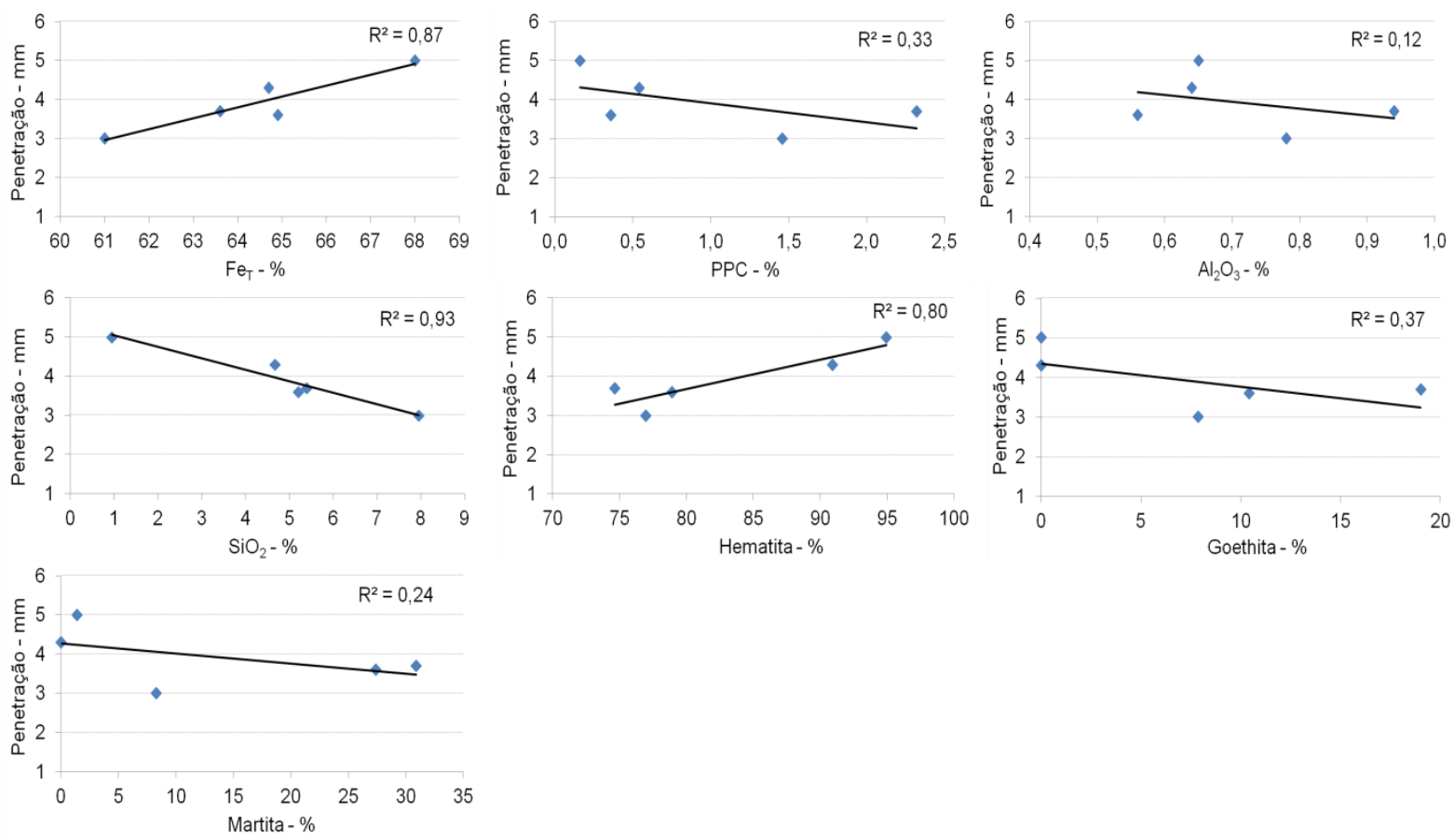

Figura 17. Relação entre o comprimento da penetração do líquido e as propriedades da fração aderente dos minérios.

* Contribuição técnica ao 44 Seminário de Redução de Minério de Ferro e Matérias-primas, 15ํ Simpósio Brasileiro de Minério de Ferro e $2^{\circ}$ Simpósio Brasileiro de Aglomeração de Minério de Ferro, 15 a 18 de setembro de 2014, Belo Horizonte, MG, Brasil. 


\section{CONCLUSÃO}

Foi avaliada a aplicação dos ensaios assimilação e penetração de fase líquida na caracterização de sinter feed.

Os minérios apresentaram comportamento diferente em altas temperaturas, dos quais aqueles com alto teor de ferro oriundo de hematita tenderam a formar líquidos com alta fluidez, assimilar pouco líquido, elevando sua difusão, consequentemente, obtendo maior resistência mecânica no sínter. Por outro lado, aqueles com baixo teor de ferro, porosos, com goethita e martita tenderam a formar líquido de baixa fluidez, assimilar muito líquido, restringindo a sua difusão, consequentemente, obtendo menor resistência mecânica no sínter.

Os ensaios implementados permitem avaliar o comportamento dos minérios em altas temperaturas, podendo auxiliar na escolha da carga de minérios mais adequada para a sinterização.

\section{Agradecimentos}

Agradecimento especial aos profissionais da NSSMC: Jun Okazaki, Yuji Fujioka e Tsumotu Okada.

\section{REFERÊNCIAS}

1 Okazaki J, Higuchi K, Hosotani Y, Shinagawa K. Influence of Iron Ore Characteristics on Penetration Behavior of Melt into Ore Layer. ISIJ International. 2003; 43 (9): 13841392.

2 Debrincat D, Loo, CE, Hutchens MF. Effect of Iron Ore Particle Assimilation on Sinter Structure. ISIJ International. 2004; 44 (8): 1308-1317.

3 Okazaki J, Nakano M, Higuchi K. Marra Mamba Ore, Its Mineralogical Properties and Evaluation for Utilization. ISIJ International. 2005; 45 (4): 427-435.

4 Otomo T, Taguchi N, Kasai E. Suppression of the Formation of Large Pores in the Assimilated Parts of Sinter Produced Using Pisolitic Ores. ISIJ International. 1996;36(11):1338-43.

5 Alencar JPSG, Pimenta FV, Botelho MEE, Vieira MB, Pimenta HP. Understanding the Behavior of Sinter Feeds At High Temperatures. 6을 International Congress on the Science and Technology of Ironmaking, ABM e ICSTI. 2012.

* Contribuição técnica ao 44 Seminário de Redução de Minério de Ferro e Matérias-primas, 15ํ Simpósio Brasileiro de Minério de Ferro e $2^{\circ}$ Simpósio Brasileiro de Aglomeração de Minério de Ferro, 15 a 18 de setembro de 2014, Belo Horizonte, MG, Brasil. 